\title{
Kinematics of global mean thermosteric sea level during 1993-2019
}

DOI: https://doi.org/10.1515/jogs-2020-0121

Received March 28, 2021; accepted June 17, 2021

\begin{abstract}
Because oceans cover $71 \%$ of Earth's surface, ocean warming, consequential for thermal expansion of sea water, has been the largest contributor to the global mean sea level rise averaged over the $20^{\text {th }}$ and the early $21^{\text {st }}$ century. This study first generates quasi-observed monthly globally averaged thermosteric sea level time series by removing the contributions of global mean sea level budget components, namely, Glaciers, Greenland, Antarctica, and Terrestrial Water Storage from satellite altimetry measured global sea level changes during 1993-2019. A baseline kinematic model with global mean thermosteric sea level trend and a uniform acceleration is solved to evaluate the performance of a rigorous mixed kinematic model. The model also includes coefficients of monthly lagged 60 yearlong cumulative global mean sea surface temperature gradients and control variables of lunisolar origins and representations for first order autoregressive disturbances. The mixed kinematic model explains 94\% (Adjusted $\left.R^{2}\right)^{1}$ of the total variability in quasi-observed monthly and globally averaged thermosteric time series compared to the $46 \%$ of the baseline kinematic model's Adjusted $R^{2}$. The estimated trend, $1.19 \pm 0.03 \mathrm{~mm} / \mathrm{yr}$., is attributed to the longterm ocean warming. Whereas eleven statistically significant $(\alpha=0.05)$ monthly lagged cumulative global mean sea surface temperature gradients each having a memory of 60 years explain the remainder transient global mean thermosteric sea level changes due to the episodic ocean surface warming and cooling during this period. The series also exhibit signatures of a statistically significant contingent uniform global sea level acceleration and periodic lunisolar forcings.
\end{abstract}

Keywords: Global mean sea level; Satellite altimetry; Global thermosteric sea level; Global mean sea surface temperature; Global sea level budget

1 Adj. $\mathrm{R}^{2}$ indicates how well the model explains the data after being adjusted for the number of parameters in the model.

*Corresponding Author: H. Bâki İz: Independent Scholar
An invalid argument can have true promises and a true conclusion.

Ian Hacking, 2001.

\section{Introduction}

Oceans cover $71 \%$ of Earth's surface and store more than $90 \%$ of the energy excess associated with anthropogenic climate change. The resulting thermal expansion due to the ocean warming is one of the leading contributors to Global Mean Sea Level, GMSL, which is well established with the quantification of the current GMSL budget (WRCP, 2018) and the adjustment of its components (Iz, et. al., 2020b, 2020c, 2020d).

In June 2007, an article by Rahmstof reported a semiempirical connection between sea level rise and globalmean sea surface temperature, GMSST, since 1900. His model projected $0.5-1.4 \mathrm{~m}$ sea level rise above the present level. Given the importance of the topic for coastal mitigation measures and climate change studies, the findings were swiftly and critically reviewed by Schmith et al. (2007). Their review revealed detrimental flows in the model and the application of the statistical methods deployed by the study thereby raised doubts about the validity of the numerical results.

Holgate et al., (2007) also commented on the investigation and reported that there is no linear relationship between global mean surface temperature and the rate of global mean sea-level change with a conclusion that the projections made by this model will not "substantially contribute to our understanding of the uncertainties in the nonlinear relationships of the climate system.” Ironically, this critical review was also incognizant of the severe first order autocorrelations in the data sets and their ramifications recognized in Schmith et al. (2007) review.

A follow-up study by Vermeer and Rahmstorf (2009) added another term with sea surface temperature gradient to the model used by Rahmstof (2007) to account for an instantaneous rise in global sea level. They discussed irrelevancy of the autocorrelations because of the robust- 
ness of their estimated findings. However, although the estimated model parameters are not significantly influenced by unaccounted positive autocorrelations in disturbances, they induce Type I errors due to their impact on the solution statistics for which they are not robust. Moreover, the unknown coefficient of the impact factor estimated in their study is reported to be negative and explained to be a physical phenomenon by the investigators. Nonetheless, the disturbances of the globally averaged sea surface temperature measurements are also highly first order autocorrelated, $\operatorname{AR}(1)$, with an autocorrelation coefficient $\rho=0.8$, $(\mathrm{Iz}, 2018)$ as in the case of satellite altimetry based GMSL time series $\rho=0.9$, (Iz and Shum, 2020c). The omission of the effect of AR(1) in calculating sea surface temperature gradients can generate negative or positive spurious trends. Therefore, the conclusions of the follow up study by Vermeer and Rahmstorf (2009) are also not reliable. Above all, ignoring the effects of AR(1) will blunder any projections/predictions to be made about the state on the Global Mean Sea level (GMSL) as demonstrated in İz and Shum (2020a).

This study is not about predictions/projections of GMSL rise since the prerequisite for such investigations is a rigorously constructed model. The current study is also limited to the Satellite Altimetry (SA) era 1993-2019 for which high resolution auxiliary time series are available for corrections.

In the following section, observed GMSL, and Global Mean Sea Surface Temperature (GMSST) time series used are briefly described. Quasi-observed Global Mean Thermosteric (GMTSL) time series are then derived from GMSL time series by correcting it for the effects of the other global mean sea level budget components, namely, Glaciers, Greenland, Antarctica, and Terrestrial Water Storage for the period 1993-2019. A baseline kinematic model with GMTSL trend and a uniform acceleration is subsequently solved to serve as a baseline to evaluate the performance of a rigorous mixed kinematic model, inclusive of control variables of lunisolar origin and unknown coefficients of monthly lagged 60 yearlong cumulative GMSST gradients.

\section{Monthly and globally averaged satellite altimetry data}

This study utilizes monthly averaged GMSL data, shown in Figure 1, which were generated using the Integrated Multi-Mission Ocean Altimeter Data. It combines sea surface heights from TOPEX/Poseidon, Jason-1, OSTM/Jason2, and Jason-3 to a common terrestrial reference frame with all inter-mission biases, range and geophysical corrections applied and placed onto a georeferenced orbit. This is a consistent data record throughout time, regardless of the instrument used (GSFC, 2020).

An earlier study by Iz and Shum (2020c) revealed that the disturbances, $\varepsilon_{t}$ of the globally and monthly averaged satellite altimetry (SA) anomalies, $h_{t}$, are highly first order autocorrelated AR(1) with an autocorrelation coefficient of $\rho$ 0.9, i.e.,

$$
h_{t}^{S A}=h_{t-1}^{S A}+\varepsilon_{t}^{S A} .
$$

In this expression, the statistical properties of the disturbances are given by,

$$
\varepsilon_{t}^{S A}=\rho \varepsilon_{t-1}^{S A}+u_{t}^{S A}, \quad 0 \leq|\rho|<1 .
$$

where the disturbances, $\varepsilon_{t}^{S A}$, are first order autocorrelated and $\rho$ refers to their autocorrelation coefficient. The white noise is $u_{t}^{S A} \sim\left(0, \sigma_{u S A}^{2}\right)$, and $\sigma_{u S A}^{2}$ is the variance of random variations (shocks/innovations). The following first differences, which are labelled as SA gradients, $G M S L_{t}$, are independent from this effect,

$$
G M S L_{t}=h_{t}^{S A}:=h_{t}^{S A}-\rho h_{t-1}^{S A}+u_{t}^{S A} .
$$

The SA gradients are displayed in Figure 1 together with the original SA observed GMSL anomalies.

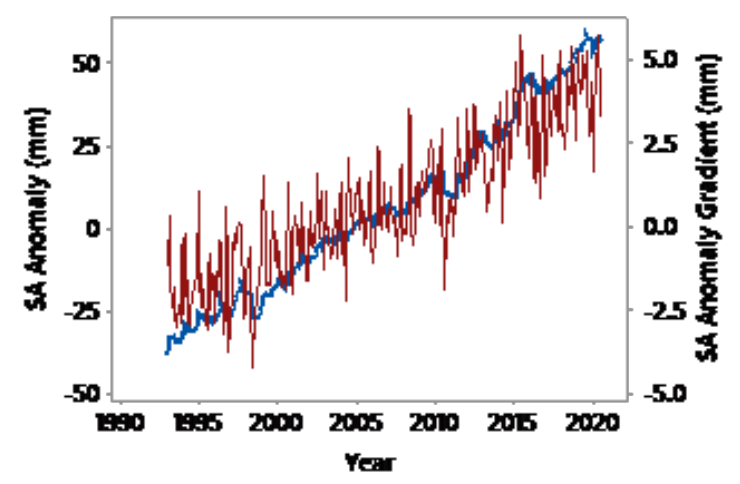

Fig. 1. Monthly averaged sea level height anomalies as observed by $\mathrm{SA}$ (in blue) and their AR(1) gradients, $\triangle \mathrm{GMSL}$. A detailed plot indicating mission periods is available at NASA's PODAAC website https://podaac.jpl.nasa.gov/. 


\section{Monthly and globally averaged thermosteric sea level data}

Temperature and salinity density changes in sea water cause volume expansion and contraction (thermosteric and halosteric components) known as steric sea level variations. The halosteric contribution to present day global mean steric sea level rise is negligible (Gregory and Lowe, 2000). Hence, this study focuses on the thermosteric sea level component.

Because the oceans cover $71 \%$ of Earth's surface, ocean thermal expansion associated with ocean warming has been one of the large contributors to global mean sea level rise averaged over the $20^{\text {th }}$ century, (Church et al., 2013). During the SA era, several research groups have produced gridded time series of temperature data for different depth levels. A full overview on in situ ocean temperature measurements is given in Abraham et al. (2013). This study will make use of HadSST4 monthly GMSST time series because of its long timespan, 1850-present (Figure 2). Detailed information about this data set can be found in Kennedy et al. (2021).

Like GMSL anomalies, GMSST anomalies exhibit autocorrelated disturbances as demonstrated by Iz (2018). The disturbances, $\varepsilon_{t}$ of the globally averaged GMSST time series are also first order autocorrelated, AR(1), with an autocorrelation coefficient $\rho 0.8$.

The following differencing operation eliminates their AR(1) effect,

$$
T_{t}-\rho T_{t-1}=\Delta T_{t}+u_{t}
$$

The resulting GMSST gradients, denoted by, $\triangle$ GMSST, are shown in Figure 2 together with the original GMSST anomalies.

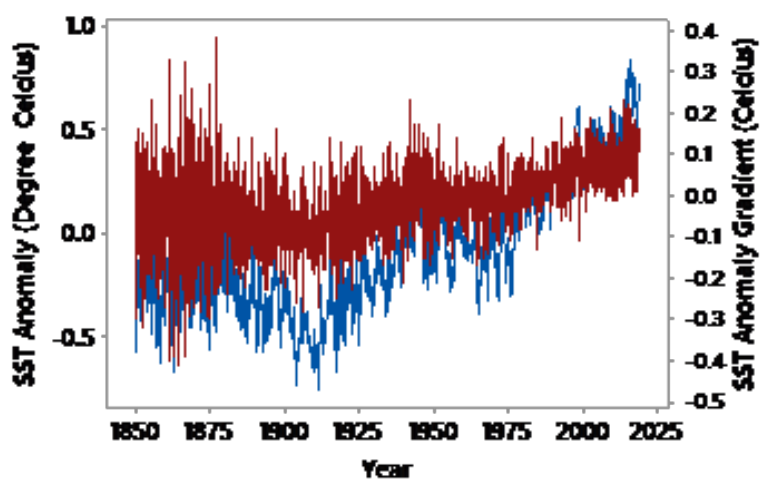

Fig. 2. GMSST (blue) and their AR(1) free gradients, $\triangle$ GMSST.
In the following section GMSL time series are corrected for the contribution of the other components of the GMSL budget due to the melting of Glaciers, Greenland, Antarctica, and terrestrial water storage (TWS), to generate quasi-observed GMTSL time series and to model their anomalies.

\section{Quasi-observed GMTSL time series}

This study is about the GMTSL. The corresponding quasiobserved monthly and globally averaged time series, $h_{t}^{G M T S L}$ is obtained by correcting GMSL observations using the trends of the other GMSL budget components, namely, Glaciers Like the other budget components, monthly Glacier time series were generated using the adjusted velocities reported by Iz and Shum 2020c in Table 1. Although not specified, Glacier time series include mountain glaciers and ice caps excluding peripheral outlet glaciers around the ice sheets, Greenland, and Antarctica. $v^{\text {Glaciers }}$, Greenland, $v^{\text {Greenland }}$, Antarctica, $v^{\text {Antartica }}$, and TWS, $v^{T W S}$, as follows,

$$
\begin{aligned}
& h_{t}^{G M T S L}:=h_{t}^{G M T S L}-\left(v^{\text {Glaciers }}+v^{\text {Greenland }}+v^{\text {Antartica }}\right. \\
& \left.+v^{T W S}\right) . t
\end{aligned}
$$

Detailed information about the GMSL budget components can be found in WCRP (2018). Using the adjusted velocities of GMSL budget components by Iz and Shum (2020a), the term within the parentheses amounts to $1.94 \mathrm{~mm} / \mathrm{yr}^{2}$ (Table 1).

Table 1. Rigorously adjusted GMSL budget component velocities during 2005-2015 (Iz and Shum 2020d). Standard errors are $1 \sigma$.

\begin{tabular}{l|l}
\hline Component & $\begin{array}{l}\text { Trend with bud- } \\
\text { get } \\
\text { constraint } \\
(\mathrm{mm} / \mathrm{yr} .)\end{array}$ \\
\hline GMSL & $3.32 \pm 0.12$ \\
Steric sea level (full depth) & $1.38 \pm 0.11$ \\
Glaciers & $0.77 \pm 0.00$ \\
Greenland & $0.83 \pm 0.03$ \\
Antarctica & $0.45 \pm 0.02$ \\
TWS from GRACE & $-0.11 \pm 0.05$ \\
Misclosure = GMSL - Sum of the com- & 0.00 \\
ponents &
\end{tabular}




\section{A baseline kinematic model}

A kinematic model for GMTSL anomalies that will be used as a reference for the mixed kinematic model in the following section is as follows,

$$
h_{t}^{G M T S L}=h_{t_{0}}^{G M T S L}+v^{G M T S L}\left(t-t_{0}\right)+\frac{1}{2} a^{G M T S L}\left(t-t_{0}\right)^{2}+\varepsilon_{t}^{G M T S L}
$$

This model will be called baseline kinematic model. In this representation, $h_{t}^{G M T S L}$ denotes monthly GMTSL observations at epochs $t=1 \ldots n$, where $n$ is the number of months. The intercept $h_{t_{0}}^{G M T S L}$ is the reference height of GMTSL time series defined at the reference epoch chosen to be in the middle of the time series. The intercept $h_{t_{0}}^{G M T S L}$ is estimated together with the global uniform velocity and contingent uniform acceleration ${ }^{2}$ parameters, $h_{t_{0}}^{G M T S L}$ and $a^{G M T S L}$, respectively.

Recognizing AR(1) properties of the disturbances, the statistical properties of this model are,

$$
\varepsilon_{t}^{G M T S L}=\rho \varepsilon_{t-1}^{G M T S L}+u_{t}^{G M T S L} \quad 0 \leq|\rho|<1,
$$

where the disturbances, $\varepsilon_{t}^{G M T S L}$, are first order autocorrelated and $\rho$ refers to their autocorrelation coefficient. The white noise is $u_{t}^{G M T S L} \sim\left(0, \sigma_{u}^{2}\right)$, and $\sigma_{u}^{2}$ is the variance of random variations (shocks/innovations).

Because the disturbances of the above observation equation are autocorrelated, the observation equations are solved using Hildreth Lu procedure (Hildreth, and $\mathrm{Lu}$, 1960), which will be abbreviated as H-L. The H-L solution for this model is listed in Table 2. The GMTSL time series are also highly first order autocorrelated, with an autocorrelation coefficient of $\hat{\rho}=0.9$.

The estimated GMTSL trend is $1.19 \pm 0.03 \mathrm{~mm} / \mathrm{yr}$., which reproduces the trend of monthly and globally averaged ARGO steric time series, $1.2 \pm 0.2 \mathrm{~mm} / \mathrm{yr}$. (NASA, 2021). The estimate is also in close agreement ${ }^{3}$ with the trend of the steric budget component, $1.38 \pm 0.11 \mathrm{~mm} / \mathrm{yr}^{2}$ listed in Table 1, which includes halosteric effects and derived from

2 The contingency of the acceleration is due to a similar uniform acceleration in GMSL during this period (Iz and Shum 2020a) and it is carried over to the quasi-observed GMTSL time series. Because the small but statistically significant non-linearity in GMSL can also be explained equally well by several forced low frequency lunisolar sub harmonics or natural sea level changes as demonstrated by Iz and Shum (2020a), its presence is contingent. In this study, the term acceleration will therefore refer to a contingent uniform acceleration of an unknown origin.

3 The null hypothesis for their difference cannot be rejected at $\alpha=$ 0.05 significance level. ensemble mean of a set of 11 direct (in situ) estimates of thermosteric sea level time series (WCRP, 2018).

The baseline kinematic model's residuals shown in Figure 3 exhibit visually perceptible episodic excursions with signatures of unmodeled transient changes in GMTSL. The Adj. $R^{2}$ statistic 45.6 percent is not an impressive model performance and correlates well with Multiple Enso Index (MEI) (Iz and Shum, 2020c). The Adj. $R^{2}$ of this model will be used to assess the performance of the mixed kinematic model elucidated in the following section.

\section{The mixed kinematic model}

The baseline kinematic model of the previous section is a basic representation of the kinematics of GMTSL variations. Because of the model's insufficient explanatory power of Adj. $R^{2}=45.6 \%$, it is not suitable for validating GMSL budget and predicting future climate assessments.

GMTSL is due to the overall ocean warming, part of which is realized through the observed Global Sea Surface (SST) measurements. SST measurements are representative of the upper $700 \mathrm{~m}$ since surface warming migrates into deeper oceans over an extended period (Rhein et al., 2013). In the interim, ocean surface experiences episodic cooling and heating as part of atmosphere-ocean interactions in shorter time scales (ibid.). For this reason, GMTSL can be represented by a long-term trend that relates GMTSL to the deep ocean warming, and the remainder anomalies can be modeled using distributed lags ${ }^{4}$ of the GMSST gradients. Previous studies by İz (2016a) and İz (2016b) have demonstrated the effectiveness of using distributed lags in modeling sea level variations at Tide Gauges, (TG). An offshoot of these models is given by,

$$
\begin{aligned}
& h_{t}^{G M T S}=h_{t_{0}}^{G M T S}+v^{G M T S}\left(t-t_{0}\right)+\frac{1}{2} a^{G M T S}\left(t-t_{0}\right)^{2} \\
& +\sum_{h=1}^{2}\left[\alpha_{h} \cos \left(\frac{2 \pi}{P_{h}}\right)\left(t-t_{0}\right)+y_{h} \sin \left(\frac{2 \pi}{P_{h}}\right)\left(t-t_{0}\right)\right] \\
& +\sum_{s=0}^{q} \beta_{s} \Delta T_{t-s}+\varepsilon_{t}^{T S} \\
& \varepsilon_{t}^{G M T S}=\rho \varepsilon_{t-1}^{G M T S}+u_{t}^{G M T S}, \quad 0 \leq|\rho|<1
\end{aligned}
$$

This is a mixed kinematic model. It is an extension of the baseline kinematic model augmented by a representation of GMSST induced contributions to the sea level variations

\footnotetext{
4 Integration of two time-series data has been occasionally used in
} modelling sea level changes. 
at shorter time scales using lagged GMSST gradients (Figure 2). In this expression, $h_{t}^{G M T S}$ is the quasi-observed GMTSL at an epoch $t$, and $u_{t}^{G M T S}$ is a stationary error term. The constant datum offset is represented by $h_{t_{0}}^{G M T S}$. It is referenced to the middle of the series. The difference $\Delta T_{t-s}$ is the lagged SST gradient at a given epoch $t$, while $s$ represents the monthly lagged cumulative marginal effect of the GMSST change in the past on the sea level observed a $t$. In this study, $\Delta T_{t-s}$, the GMSST gradient, is in monthly intervals and quantified by Eq. 4. GMSST anomalies contribute to each monthly GMTSL anomalies cumulatively with 60 yearlong effects, for each one of the $q=60 \times 12=720$ months. The 60 yearlong cumulative monthly lags are an ad hoc period limited by the time span of the available historical GMSST time series. The unknown lag-weights, $\beta_{s}$, scale monthly cumulative contribution of GMSST gradients, $\Delta T_{t-s}$, over 60 years to the quasi-observed monthly GMTSL anomalies.

The kinematic model also includes components of two periodic variables of lunisolar origin with periods $P=$ 18.6 and $11.1 \mathrm{yr}$. Their presence in sea level variations was demonstrated earlier by Iz (2014) at globally distributed TG stations. These periodic variations are well-known forced variations of astronomical origin and serve as carrier frequencies in combination with natural sea level changes generating sub and super harmonic periodic changes in the sea level. They are carried over to the GMTSL quasiobservations via GMSL time series in Eq. 5. Moreover, stationary long-period tides introduce vertical temperature mixing between SST and cold bottom temperatures thereby, it is the source of GMTSL variations. On the other hand, the effect of the solar radiation periodicity is symbiotically related to the ocean surface warming caused by solar irradiation and becomes estimable due to the presence of GMSST gradients in the mixed kinematic model. Each period introduces two parameters, $\alpha_{h}, y_{h}$ for the sine and cosine components from which the amplitudes, $a_{h}$, and the phase angles of the periodic terms are determined.

In total, the model has 726 unknown parameters 719 of which are initially attributed to the distributed lags. This is certainly an over parametrization given 311 monthly GMTSL quasi-observations during 1993-2019. However, the number of distributed parameters reduces to eleven parameters using a stepwise solution for the mixed kinematic model in which the contribution of each parameter is evaluated separately, one by one, and keeping only the ones that are statistically significant at $\alpha=0.05$ significance level. The final model consists of only 17 statistically significant parameters shown in Figure 4 with the degrees of freedom, DF $=293$.
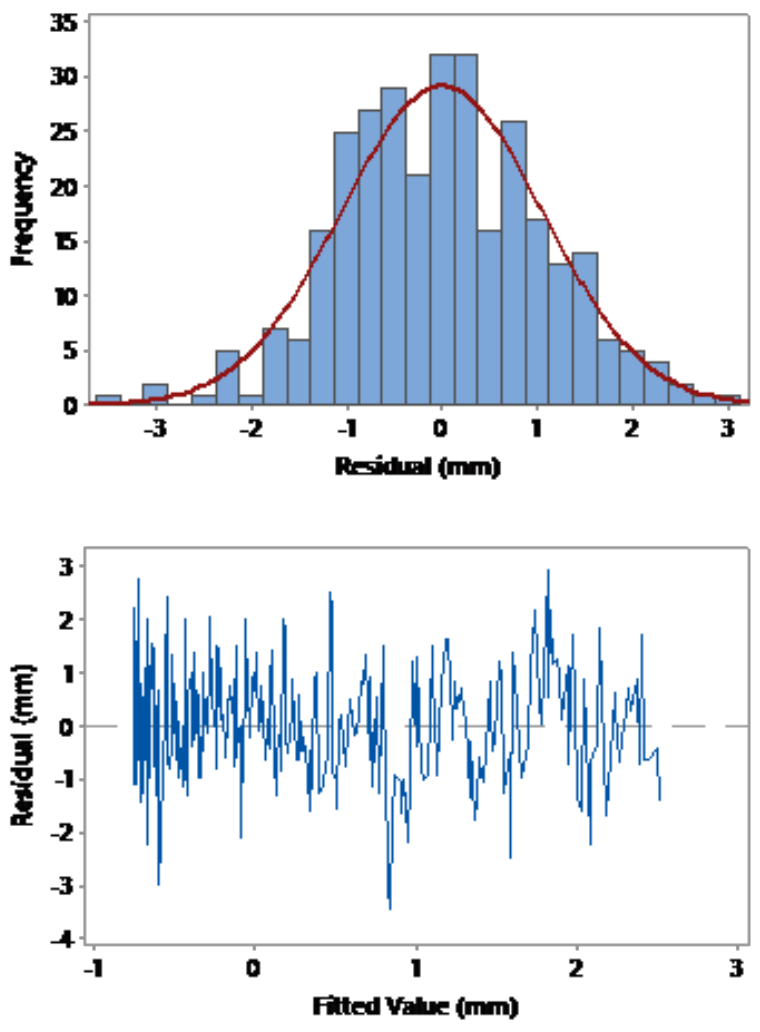

Fig. 3. Residuals of the baseline kinematic model solution exhibit unmodeled episodic excursions. They correlate well with MEI (Iz and Shum 2020c).

The model given by Eq. 8 and Eq. 9 is solved using $\mathrm{H}-\mathrm{L}$ procedure. The iteratively estimated AR(1) correlation coefficient of the disturbances is reduced from 0.9 down to 0.4 for the mixed kinematic model revealing that the autocorrelation is partially induced by the unmodeled ocean surface warming effect. The standard error (SE) of the solution is larger than the baseline kinematic model's SE because of the newly added parameters. Meanwhile, DW statistic differs markedly from its expected value of 2 indicating persistent deviations in residuals from randomness that are now detectable by the removal of unmodeled anomalies due to the ocean surface warming. These unexplained variations are clearly delineated in residuals vs. fitted value plot (Figure 4), but their episodicity is less prevalent. These are unmodeled events (bursts/shocks/innovations) that drive the AR(1) effects in GTMSL anomalies in the baseline kinematic model solution. The physical origin(s) of these triggering events needs to be investigated in future studies.

Despite the unmodeled residual events, the mixed kinematic model explains $94 \%$ of the total variation in GMTSL, twice as much compared to the baseline kine- 

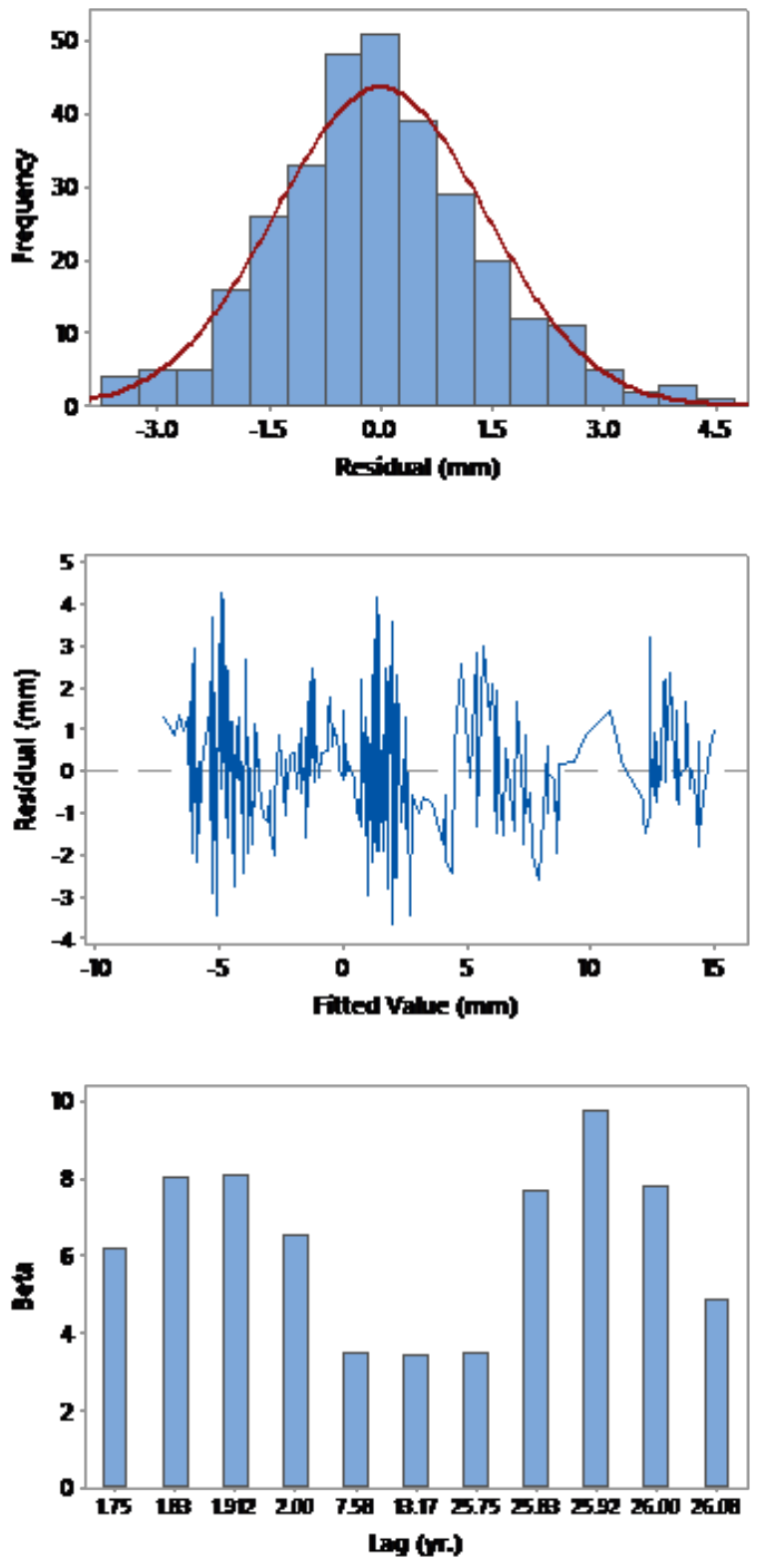

Fig. 4. Residuals of the mixed kinematic model solution now exhibit visually perceptible shocks/innovations (in red). Beta lag-weights are statistically significant at $\alpha=0.05$ level.

matic model solution without the GMSST gradients. The final solution's $R^{2}$ statistic is also adjusted for the number of additional parameters. This is a considerable improvement in the explanatory power of the kinematic-mixed model, which will influence GMTSL predictions as well as GMSL budget closure. The estimated monthly cumulative lag weights of the GMSST gradients are listed in Table 3 and illustrated in Figure 4. The estimated $\beta$ weights are all statistically significant at $\alpha=0.05$ level and are independent of each other and the other model parameters as in- dicated by their variance inflation factors, (VIF), tabulated in Table 1.

The estimate of the GMTSL trend of the mixed kinematic model compared to the baseline kinematic model trend estimate is unchanged despite the introduction of the newly introduced model parameters. This outcome suggests that the contribution of the ocean surface warming to the long term GTMSL trend is not as large as the contribution of the lagged GMSST gradients that account for the sea level variations in the upper ocean.

Components of the periodic variations due to the lunar node and solar radiation are also statistically significant. Their effects estimated from the GMSL series directly using the baseline kinematic model are not significant because of the time span of the SA measurements and the random noise. With the introduction of noise reducing lagged GMSST gradients in the mixed kinematic model, they become estimable. Note that the explanatory contribution of the solar radiation/irradiation periodicity to the total explained variation is second to the variation explained by the GMTSL trend, i.e., it is larger than the estimated GMTSL acceleration's contribution (Adj. MS $=250$ vs. 190 respectively, Table 3).

Another important revelation of the mixed kinematic model in comparison to baseline kinematic model is that the acceleration estimates are comparable, $0.100 \pm 0.025$ $\mathrm{mm} / \mathrm{yr}^{2}$ vs. $0.061 \pm 0.006 \mathrm{~mm} / \mathrm{yr}^{2}$. Their robustness suggests that the estimated acceleration cannot be attributed exclusively to the warming of the upper ocean during 1993-2019.

\section{Conclusion}

This study clarified the debate regarding the impact of a semi-empirical connection between GMSL rise and GMSST stated in the introduction section. Using a rigorously established kinematic model inclusive of the critical suggestions by Schmith et. al., (2007), the effect of the long term GMTSL trend due to the deep ocean warming over an extended period based on the quasi-observed GMTSL is estimated. The remainder GMTSL anomalies are shown to be caused by the ocean surface warming and can effectively be represented by monthly lagged 60 yearlong cumulative GMSST gradients. The robustness of an estimated contingent uniform acceleration with and without GMSST effects lessens the likelihood of its origin being solely due to the warming of the ocean surface. The model improvements will have marked contributions on reducing GMSL bud- 
Table 2. H-L solution statistics for the baseline and mixed kinematic models. All the estimated parameters are statistically significant at alpha $=0.05$.

\begin{tabular}{|c|c|c|c|c|c|c|c|}
\hline $\begin{array}{l}\text { Kinematic } \\
\text { Model }\end{array}$ & Parameters & $\begin{array}{l}\text { Trend } \\
\mathrm{mm} / \mathrm{yr} .\end{array}$ & $\begin{array}{l}\text { Acc. } \\
\mathrm{mm} / \mathrm{yr}^{2}\end{array}$ & $\begin{array}{l}\mathrm{SE} \\
\mathrm{mm}\end{array}$ & $\begin{array}{l}\text { Adj. } \\
R^{2} \%\end{array}$ & DW & $\operatorname{AR}(1)$ \\
\hline Baseline & Trend \& Acc. & $\begin{array}{l}1.22 \\
\pm 0.09\end{array}$ & $\begin{array}{l}0.100 \\
\pm 0.025\end{array}$ & 1.06 & 45.6 & 1.09 & 0.9 \\
\hline Mixed & $\begin{array}{l}\text { Trend \& Acc. \& } \\
\text { GMSST Grad. }\end{array}$ & $\begin{array}{l}1.19 \\
\pm 0.03\end{array}$ & $\begin{array}{l}0.061 \\
\pm 0.006\end{array}$ & 1.46 & 94.3 & 0.41 & 0.4 \\
\hline
\end{tabular}

Table 3. The mixed kinematic model's $L S$ solution statistics. The parameters, $\alpha_{h}, \gamma_{h}$ are the estimated parameters for the sine and cosine components for the two periodic variables of lunisolar origin with periods $P=18.6$ and $11.1 \mathrm{yr}$. Lag-weights, are denoted by $\beta_{s}$ where subscripts refer to the lags in years. All estimates are statistically significant $(\alpha=0.05)$.

\begin{tabular}{l|l|l|l|l}
\hline Parameter & Estimate & SE & VIF & Adj. MS \\
\hline Constant & 0.08 & 0.17 & N/A & 682.08 \\
Trend $(\mathrm{mm} / \mathrm{yr})$. & 1.19 & 0.03 & 1.88 & 4458.94 \\
Acceleration & 0.061 & 0.006 & 1.25 & 189.50 \\
$\left(\mathrm{~mm} / \mathrm{yr}^{2}\right)$ & & & & \\
$\alpha_{11.1}(\mathrm{~mm})$ & -0.67 & 0.22 & 1.14 & 20.41 \\
$\gamma_{11.1}(\mathrm{~mm})$ & 2.32 & 0.21 & 1.26 & 249.95 \\
$\alpha_{18.6}(\mathrm{~mm})$ & -1.27 & 0.21 & 1.10 & 74.15 \\
$\beta_{1.7}\left(\mathrm{~mm} /{ }^{\circ} \mathrm{C}\right)$ & 6.18 & 1.79 & 1.28 & 25.34 \\
$\beta_{1.8}\left(\mathrm{~mm} /{ }^{\circ} \mathrm{C}\right)$ & 8.05 & 1.91 & 1.46 & 37.89 \\
$\beta_{1.9}\left(\mathrm{~mm} /{ }^{\circ} \mathrm{C}\right)$ & 8.08 & 1.92 & 1.49 & 37.74 \\
$\beta_{2.0}\left(\mathrm{~mm} /{ }^{\circ} \mathrm{C}\right)$ & 6.53 & 1.79 & 1.30 & 28.23 \\
$\beta_{7.6}\left(\mathrm{~mm} /{ }^{\circ} \mathrm{C}\right)$ & 3.49 & 1.71 & 1.17 & 8.82 \\
$\beta_{13.2}\left(\mathrm{~mm} /{ }^{\circ} \mathrm{C}\right)$ & 3.41 & 1.65 & 1.10 & 9.13 \\
$\beta_{25.7}\left(\mathrm{~mm} /{ }^{\circ} \mathrm{C}\right)$ & 3.5 & 1.65 & 1.22 & 9.62 \\
$\beta_{25.8}\left(\mathrm{~mm} /{ }^{\circ} \mathrm{C}\right)$ & 7.72 & 1.75 & 1.4 & 41.36 \\
$\beta_{25.9}\left(\mathrm{~mm} /{ }^{\circ} \mathrm{C}\right)$ & 9.79 & 1.74 & 1.38 & 67.71 \\
$\beta_{26.0}\left(\mathrm{~mm} /{ }^{\circ} \mathrm{C}\right)$ & 7.79 & 1.75 & 1.41 & 42.18 \\
$\beta_{26.1}\left(\mathrm{~mm} /{ }^{\circ} \mathrm{C}\right)$ & 4.90 & 1.65 & 1.27 & 18.68 \\
\hline
\end{tabular}

get misclosures and improving GMSL predictions, which needs to be assessed in future studies.

\section{Appendix: List of abbreviations}

\section{AR(1) First Order Autocorrelation}

DW Durbin-Watson

GMSL Global Mean Sea Level

GMSST Global Mean Sea Surface Temperature

GMTSL Global Mean Thermosteric Sea level

GRACE Gravity Recovery and Climate Experiment

GSFC Goddard Space Flight Center

HadSST Hadley Center Sea Surface Topography

H-L Hildreth-Lu

JASON Joint Altimetry Satellite Oceanography Network

OLS Ordinary Least Squares

5 Adj. MS: Adjusted Mean Square.
OSTM Ocean Surface Topography Mission

SA Satellite Altimetry

SE Standard Error

SST Sea Surface Temperature

TOPEX Topography Experiment

TG Tide Gauge

TWS Terrestrial Water Storage

VIF Variance Inflation Factor

\section{References}

Abraham, J. P., M. Baringer, N. L. Bindoff, T. Boyer, L. J. Cheng, J. A. Church, J. L. Conroy, C. M. Domingues, J. T. Fasullo, J. Gilson, G. Goni, S. A. Good ,J. M. Gorman, V. Gouretski, M. Ishii, G. C. Johnson, S. Kizu, J. M. Lyman, A. M. Macdonald, W. J. Minkowycz, S. E. Moffitt, M. D. Palmer, A. R. Piola F. Reseghetti, K. Schuckmann, K. E. Trenberth, I. Velicogna, J. K. Willis, 2013, A review of global ocean temperature observations: Implications for ocean heat content estimates and climate change, Rev. Geophys., 51, 450- 483. . 
Church, J. A., Clark, P. U., Cazenave, A., Gregory, J. M., Jevrejeva, S., Levermann, A., Merrifield, M. A., Milne, G. A., Nerem, R. S., Nunn, P. D., Payne, A. J., Pfeffer, W. T., Stammer, D. and Unnikrishnan, A. S., 2013, 'Sea level change', in: Stocker, T. F., Qin, D., Plattner, G.-K., et al. (eds), Climate change, 2013: The physical science basis. Contribution of Working Group I to the Fifth Assessment Report of the Intergovernmental Panel on Climate Change, Cambridge University Press, Cambridge; New York, pp. 1137-1216.

Gregory, J. M., , and J. A. Lowe, 2000, Predictions of global and regional sea-level rise using AOGCMs with and without flux adjustment. Geophys. Res. Lett., 27 , 3069-3072.

GSFC, 2020, Global Mean Sea Level Trend from Integrated Multi-Mission Ocean Altimeters TOPEX/Poseidon, Jason-1, OSTM/Jason-2, and Jason-3 Version 5.0 Ver. 5.0 PO.DAAC, CA, USA. Dataset accessed [2021-01-14] at http://dx.doi.org/10. 5067/GMSLM-TJ150.

Hacking, I., 1990, The Taming of Chance. Cambridge University Press.

Holgate S, Jevrejeva S, Woodworth P, Brewer S., 2007, Comment on "a semi-empirical approach to projecting future sea-level rise." Science 317:1866b.

İz H.B., C. K. Shum, 2020a: Recent and future manifestations of a contingent global mean sea level acceleration, J. Geod. Sci., Vol. 10, pp. 153-162.

İz H.B, C. K. Shum., 2020b, Year by year closure adjustment of global mean sea level budget with lumped snow, water vapor, and permafrost mass components, J. Geod. Sci., Vol. 10: pp. 83-90.

İz H.B., C.K. Shum, 2020c, Certitude of a global sea level acceleration during the satellite altimeter era, J. Geod. Sci., Vol. 10, pp. 29-40.

İz H.B. and Shum C.K., 2020d, A statistical protocol for a holistic adjustment of global sea level budget, J. Geod. Sci, Vol. 10, pp. 1-6.

İz H.B., Yang T.Y., Shum C.K. and Kuo C.Y., 2019, The rigorous adjustment of the global mean sea level budget during 2005-2015, Geodesy and Geodynamics, DOI: 10.1016/j.geog.2020.03.
İ H.B., 2018, Is the global sea surface temperature rise accelerating? Geodesy and Geodynamics, 1-7.

İz H.B., C.K. Shum, C.Y. Kuo, 2018, Sea Level Accelerations at Globally Distributed Tide Gauge Stations During the Satellite Altimetry Era, J. Geod. Sci. Vol. 8, pp. 130-135.

İz H.B., 2016a, Thermosteric Contribution of Warming Oceans to the Global Sea Level Variations, J. Geod. Sci., Vol. 6, pp. 130-138.

İz H.B., 2016b, The Effect of Warming Oceans at a Tide Gauge Station, J. Geod. Sci., Vol. 6, pp. 69-79.

İz H.B., 2014, Sub and Super Harmonics of the Lunar Nodal Tides and the Solar Radiative Forcing in Global Sea Level Changes, J. Geod. Sci., Vol. 4, pp. 150-165.

Kennedy, J.J., Rayner, N.A., Atkinson, C.P., and Killick, R.E. (2019), An ensemble data set of sea surface temperature change from 1850: the Met Office Hadley Centre HadSST.4.0.0.0 data set. Journal of Geophysical Research: Atmospheres, 124.

NASA, 2021, https://sealevel.nasa.gov/understanding-sea-level/ key-indicators/steric-height, Credit: NCEI/NOAA, accessed on June 2021.

Rahmstorf, S., 2007, A semi-empirical approach to projecting future sea-level rise. Science, 315, 368-370.

Rhein, M., S.R. Rintoul, S. Aoki, E. Campos, D. Chambers, R.A. Feely, S. Gulev, G.C. Johnson, S.A. Josey, A. Kostianoy, C. Mauritzen, D. Roemmich, L.D. Talley and F. Wang, 2013, Observations: Ocean. In: Climate Change 2013: The Physical Science Basis. Contribution of Working Group I to the Fifth Assessment Report of the Intergovernmental Panel on Climate Change [Stocker, T.F., D. Qin, G.-K. Plattner, M. Tignor, S.K. Allen, J. Boschung, A. Nauels, Y. Xia, V. Bex and P.M. Midgley (eds.)]. Cambridge University Press, Cambridge, United Kingdom and New York, NY, USA.

Schmith T., S. Johansen, P. Thejll, 2007, Comment on "A SemiEmpirical Approach to Projecting Future Sea-Level Rise" Science 317, 1866.

WCRP Global Sea Level Budget Group: Global sea-level budget 1993-present, 2018, Earth Syst. Sci. Data, 10, 1551-1590, https://doi.org/10.5194/essd-10-1551-2018. 